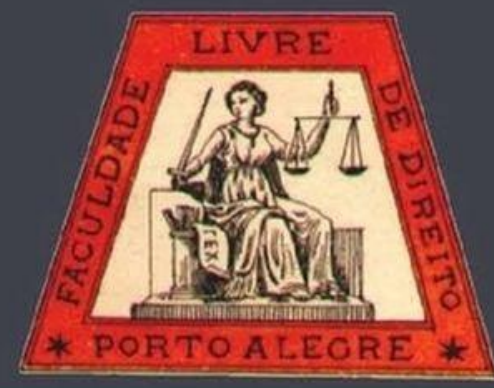

\title{
Análise crítica da teoria dos direitos humanos na obra de Michel Villey
}

A critical analysis of the Michel Villey's Human Rights theory

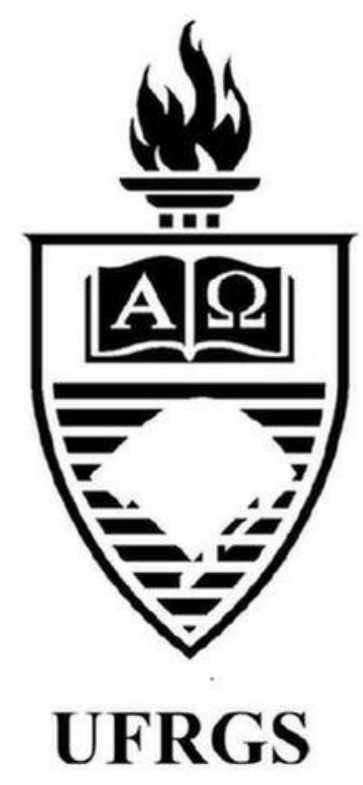

\author{
Gustavo Rabay Guerra
}

Universidade Federal da Paraíba

Henrique Jerônimo Bezerra Marcos

Universidade Federal da Paraíba 


\title{
Análise crítica da teoria dos direitos humanos na obra de Michel Villey
}

\author{
Critical analysis of Michel Villey's Human Rights theory
}

Gustavo Rabay Guerra *

\author{
Henrique Jerônimo Bezerra Marcos ${ }^{* *}$
}

\section{REFERÊNCIA}

GUERRA, Gustavo Rabay; MARCOS, Henrique Jerônimo Bezerra. Análise crítica da teoria dos direitos humanos na obra de Michel Villey. Revista da Faculdade de Direito da UFRGS, Porto Alegre, n. 40, p. 61-79, ago. 2019.

\section{RESUMO}

Este artigo tem por objeto a Teoria dos Direitos Humanos em Michel Villey. Seu objetivo é apresentar uma contestação à alegação de Michel Villey de que os direitos humanos não podem ser considerados Direito. Para tanto, realiza uma apresentação da Teoria dos Direitos Humanos em Michel Villey, passando pela criação dos direitos humanos em Thomas Hobbes, a inversão de objetivos dos direitos humanos em John Locke e a expansão dos direitos humanos em Christian Wolff. Em seguida passa a apresentar a crítica de Michel Villey aos direitos humanos e as falhas deste autor ao realizar suas acusações, haja vista a possibilidade de solução das contradições (colisões) entre os direitos humanos, além de que não se pode confundir o critério de validade da norma com sua eficácia. O trabalho conclui pela juridicidade dos direitos humanos ao demonstrar que a suposta contradição não seria razão para retirar esta qualidade.

\section{PALAVRAS-CHAVE}

Filosofia do Direito. Direitos Humanos. Michel Villey.

\begin{abstract}
The present work deals with the General Theory of Human Rights in Michel Villey. Its purpose is to present a challenge to Michel Villeys' claim that human rights are not legal norms. To do so, the text presents the General Theory of Human Rights in Michel Villey, including the creation of human rights by Thomas Hobbes, the changing perspective attributed to John Locke and the numerical expansion of human rights attributed to Christian Wolff. The text then presents Michel Villeys' critics of human rights and the problems with those critics; specifically, that the given conflicts between norms aren't sufficient to declare that they aren't legal norms, other than that, the text points that in his critics Michel Villey confuses the concepts of validity of the norm with its effectiveness. The work concludes that human rights are legal norms and its supposed intrinsic contradiction is not sufficient to withdraw this quality.
\end{abstract}

\section{KEYWORDS}

Philosophy of Law. Human Rights. Michel Villey.

\section{SUMÁRIO}

Introdução. 1 Sucintas considerações sobre a inexistência de direitos humanos antes do século XVII. 2 O surgimento dos direitos humanos, Thomas Hobbes e John Locke. 3 A hipertrofia dos direitos humanos em Christian Wolff e as críticas de Michel Villey à linguagem contraditória dos direitos humanos. 4 A falha na acusação de Michel Villey: um desfecho à suposta contradição inata dos direitos humanos. 5 Conclusão. Referências bibliográficas.

\footnotetext{
* Advogado e professor do CCJ-UFPB. Doutor em Direito, Estado e Constituição pela UNB e Mestre em Direito Público pela UFPE. E-mail: rabay@rbpadvogados.com.br.

Advogado. Mestrando em Ciências Jurídicas pela Universidade Federal da Paraíba - UFPB. E-mail: henriquemarcos5@gmail.com
} 


\section{INTRODUÇÃO}

De forma majoritária, os juristas contemporâneos entendem que os direitos humanos são uma boa ideia. Afinal, o instituto é enxergado como um dos principais instrumentos dos indivíduos contra a opressão perpetrada pelo Estado e até mesmo por outros indivíduos (não podemos ignorar a força que ganha a ideia de "eficácia horizontal" dos direitos humanos). Em livros, palestras e discursos, os direitos humanos andam junto com a ideia do progresso da humanidade.

Sendo assim, não há dúvidas de que na conjuntura atual passamos por uma fase de "Humanização do Direito" ou "Jusfundamentalização do Direito" onde encontramos apelos aos direitos humanos em todas as áreas da Ciência Jurídica; os direitos humanos e a proteção dos indivíduos tornam-se o ápice do Direito. É seguro dizer que o indivíduo (não mais o Estado ou qualquer outro ente fictício) torna-se o protagonista inconteste dos trabalhos jurídicos.

Neste contexto, a maioria dos escritores desta área busca fundamentar a supremacia dos direitos humanos em um passado longínquo, mencionando o aparecimento da proteção dos indivíduos desde Zaratustra na Pérsia Antiga, Hamurabi e não esqueçamos da sempre aludida "Antígona" de Sófocles. Vivendo neste meio, quando nos deparamos com um autor que afirma que os direitos humanos só aparecem no Século XVII e surgem com objetivo de fundamentar o poder absoluto do monarca, não há como não se sobressaltar.

É esta a ideia de Michel Villey (19141988) a respeito dos direitos humanos. Este filósofo, historiador e (de seu modo) jurista é um autor ímpar. Seja por ser um dos únicos contemporâneos que se atreve a criticar de forma incauta a "religião dos direitos humanos", seja pela sua metodologia pouco ortodoxa. Dentro de tantas críticas que faz aos direitos humanos, menciona que estes são irrealizáveis, ineficazes, insustentáveis e, especialmente, contraditórios; não consegue admitir a possibilidade de enunciarmos tantos direitos supostamente incompatíveis e, justamente por isso, afirma que estes não podem ser Direito. Pasmem: os direitos humanos não seriam Direito. Confessamos que esta provocação nos é irresistível.

Deste modo, o presente trabalho partiu com objetivo de rebater esta crítica de Michel Villey. Pretendíamos apenas demonstrar que o fato dos direitos humanos serem - supostamente - contraditórios, não seria suficiente para os excluirmos do Direito. No entanto, no decorrer da nossa pesquisa, percebemos que não seria possível rebater a crítica de Villey sem apresentar suas premissas antecedentes. Sendo assim, foi preciso incluir no trabalho uma parte substancial onde apresentaremos as principais ideias do autor a respeito dos direitos humanos. De toda feita, o objeto do presente trabalho é a Teoria dos Direitos Humanos em Michel Villey, em especial, sua crítica quanto à suposta linguagem intrinsecamente contraditória dos direitos humanos.

Nosso problema, portanto, é saber se de fato a crítica de Michel Villey está correta, ou seja, se em razão desta suposta linguagem contraditória os direitos humanos não seriam Direito. Dito de outra forma: estaria Michel Villey correto ao afirmar que os direitos humanos não são Direito, haja vista possuírem uma linguagem supostamente contraditória?

Nossa hipótese é a de que Villey está incorreto; ainda que se admita que os direitos humanos sejam contraditórios à primeira vista se partirmos de uma análise normativa a partir das técnicas das Teorias Interna e Externa seria possível solucionar quaisquer contradições que por ventura apareçam. Ademais, entendemos com base na Teoria Geral da Norma Jurídica que não é possível dizer que uma norma não é 
Direito apenas em razão de sua ineficácia concreta.

Como já adiantamos acima, nosso objetivo principal é rebater a crítica de Michel Villey, demonstrando que, ainda que se admita que os direitos humanos possuam uma linguagem contraditória, é possível superar estas contradições a partir da aplicação da hermenêutica dos direitos humanos; além disso, objetiva-se demonstrar que esta crítica é juridicamente incorreta, haja vista confundir eficácia e validade da norma. Como objetivo secundário, propomos, também, uma apresentação da Teoria dos Direitos Humanos em Michel Villey.

Nosso referencial teórico, ou seja, a base teórica que servirá para respaldar a pesquisa, será caracterizado essencialmente pelos textos do próprio Michel Villey, tendo em vista que o objeto da pesquisa é, rigorosamente, a Teoria dos Direitos Humanos neste autor. No que diz respeito à bibliografia referencial, novamente, destaca-se a obra de Michel Villey, mas, ao lado deste autor, faremos uso de bibliografia especializada na área de Direitos Humanos e Direitos Fundamentais. No tocante ao recorte metodológico, nossa opção quanto ao método de abordagem será o método indutivo, quanto ao método de procedimento, o monográfico, e, por fim, quanto à técnica de pesquisa, nosso levantamento será eminentemente bibliográfico.

Quanto à organização, nos termos do mencionado acima, nosso trabalho iniciará com uma parte expositiva, traçando um desenvolvimento das ideias de Michel Villey quanto aos direitos humanos. Neste momento traremos algumas considerações do autor a respeito da inexistência dos direitos humanos antes do Século XVII. Feitas estas observações, passaremos para a invenção dos direitos humanos em Thomas Hobbes e, então, para a inversão dos objetivos dos direitos humanos em
John Locke. A seguir, traremos a fase de expansão dos direitos humanos em Christian Wolff, na Revolução Francesa e na Declaração Universal dos Direitos Humanos - DUDH. Neste momento apresentaremos a principal crítica de Villey aos direitos humanos: sua alegação quanto à falta de juridicidade dos direitos humanos em razão de sua suposta linguagem contraditória.

Finda esta parte expositiva, o trabalho passa a apresentar as razões pelas quais não congregamos com as críticas de Villey. Neste momento nos utilizaremos das Teorias Interna e Externa para demonstrar que a suposta linguagem contraditória dos direitos humanos não é insolucionável e não faz com que estes deixem de ser direito, pelo contrário, a colisão de direitos é um fenômeno tipicamente jurídico. Além disso, demonstra-se que, com base na Teoria Geral da Norma Jurídica não se pode confundir a validade da norma com sua eficácia, haja vista tratarem-se de elementos distintos e independentes.

Feita a introdução do nosso trabalho, passaremos, portanto, para a análise da Teoria dos Direitos Humanos em Michel Villey, especificamente as considerações do autor a respeito da inexistência dos direitos humanos antes do Século XVII.

\section{SUCINTAS CONSIDERAÇÕES SOBRE A INEXISTÊNCIA DE DIREITOS HUMANOS ANTES DO SÉCULO XVII}

Como mencionado acima, antes de ingressar no estudo dos direitos humanos em Michel Villey, é preciso observar que, de acordo com o autor, os direitos humanos são uma criação do Século XVII. ${ }^{1}$ Para chegar à esta conclusão, Villey realiza uma desconstrução da difundida ideia doutrinaria de que é possível

\footnotetext{
${ }^{1}$ VILLEY, Michel. O Direito e os Direitos Humanos. Tradução de Maria Ermantina de Almeida Prado Galvão.
} São Paulo: WMF Martins Fontes, 2007, p. 137. 
extrair a noção de direitos humanos desde os tempos antigos. $^{2}$

Primeira consideração: não existem direitos humanos na Grécia Antiga. No seu trabalho, o autor argumenta que na tradição aristotélica a palavra "Justiça" (dikaiosyne) é polissêmica, podendo significar a Justiça Particular (perspectiva do Direito como Relação Intersubjetiva), a Justiça Geral (ideia da justiça como soma de todas virtudes a serviço da ordem e harmonia universal) e a Justiça Legal (observância das leis morais). No entanto, em nenhum destes significados é possível extrair direitos humanos. ${ }^{3}$ Ademais, não se pode ignorar que em Aristóteles o Direito só existe na pólis sendo, deste modo, decorrência da sociedade e não do indivíduo. Melhor dizendo: na tradição aristotélica não existe Direito no indivíduo e nem direito do indivíduo, o Direito é do grupo político. Desta feita, é impossível extrair da filosofia helenística quaisquer ideias de direitos do homem. ${ }^{4}$

Segunda consideração: não existem direitos humanos na Roma Antiga. Na tradição romana a justitia também é polissêmica, no entanto, além dos significados apresentados acima, pode, também, ser compreendida como a ordem do mundo de toda a humanidade (jus naturale). Entretanto, aqui também não é possível extrair os direitos humanos, haja vista que não se trata de um instituto voltado a salvaguardar o indivíduo, mas estabelecer as origens da ordem universal das coisas. ${ }^{5} \mathrm{~A}$ bem da verdade, como diria Villey, o Direito Natural não teve grande repercussão jurídica em Roma.

\footnotetext{
${ }^{2}$ VILLEY, Michel. O Direito e os Direitos Humanos. Tradução de Maria Ermantina de Almeida Prado Galvão. São Paulo: WMF Martins Fontes, 2007, p. 137.

${ }^{3}$ Ibidem, p. 94.

${ }^{4}$ Id. A Formação do Pensamento Jurídico Moderno. Tradução de Cláudia Berliner. São Paulo: Martins Fontes, 2005. p. 698.

${ }^{5}$ Id. O Direito e os Direitos Humanos. Tradução de Maria Ermantina de Almeida Prado Galvão. São Paulo: WMF Martins Fontes, 2007. p. 95.
}

O protagonista do Direito Romano é o Direito Civil ("a autêntica invenção romana foi o direito civil"). ${ }^{6}$ No entanto, aqui também não há espaço para extrairmos os direitos humanos. Afinal, no Corpus Juris Civilis o homem não tem direito o homem não é a matéria a ciência jurídica, quando muito "apenas homens têm uns direitos diversos". ${ }^{7}$ Não existe ainda a noção de direito subjetivo.

Terceira consideração: também não é possível afirmarmos a existência de direitos humanos na Filosofia Canônica. Em que pese o autor confesse que a noção contemporânea dos direitos humanos tem uma forte dívida com as construções teológicas da doutrina judaicocristão, não é possível falar que já existiam direitos humanos. ${ }^{8}$ De acordo com o autor, não podemos confundir a Justiça Divina com a Justiça Particular; quando a Justiça Divina confere ao Homem primazia sobre todas as coisas terrenas, inclusive as criaturas inferiores, não estabelece "Direito" sobre estas coisas. Em suma: não podemos confundir os conceitos de dominium com o de proprietas. ${ }^{9}$ Sendo assim, em que pese os direitos humanos tenham como fundo ideológico a teologia cristã, eles não encontram na Filosofia Canônica da Idade Média o seu berço, apenas uma inspiração "desviada". Não existiam, ainda, os direitos humanos. ${ }^{10}$

Em conclusão, Villey é taxativo ao afirmar que os direitos humanos não existiam na Filosofia Canônica e, muito menos, na Antiguidade, seja em Roma, seja na Filosofia Helenística. Os direitos humanos surgem apenas no Século XVII. ${ }^{11}$ Como já fora dito, entendemos necessário realizar esta construção de antepassados históricos com base na obra deste autor haja vista que muito do que será

\footnotetext{
${ }^{6}$ Ibidem, p. 96.

${ }^{7}$ Ibidem, p. 102.

${ }^{8}$ Ibidem, p. 107.

${ }^{9}$ Ibidem, p. 135.

${ }^{10}$ Ibidem, p. 138.

${ }^{11}$ Ibidem, p. 137.
} 
apresentado a seguir demanda a noção do que fora acima exposto. A seguir passaremos ao estudo da invenção dos direitos humanos.

\section{O SURGIMENTO DOS DIREITOS HUMANOS, THOMAS HOBBES E JOHN LOCKE}

Como fora afirmado acima, de acordo com Villey os direitos humanos não surgem na Filosofia Canônica, nem em Roma e, nem possui origem na Filosofia Grega. Os direitos humanos são uma concepção moderna, especificamente do século XVII. ${ }^{12}$ No entanto, também como já fora dito, os direitos humanos têm como fundo ideológico a teologia cristã. A Santa Escritura é sua primeira fonte, em que pese tenha sido corrompida em três aspectos, de acordo com Villey. ${ }^{13}$

O primeiro aspecto da corrupção diz respeito ao desprezo à tradição. Em uma fase de antítese ao cristianismo medieval, os pensadores modernos tentam se afastar da teologia católica e desenvolvem uma teologia moderna que flerta com o deísmo: "a Cristo vem substituir-se o Deus produzido pela razão do Homem". ${ }^{14} \mathrm{O}$ autor vai além: "anuncia-se a religião futura [...] transferência para o Homem da adoração conferida anteriormente a Deus". ${ }^{15}$

O segundo aspecto da corrupção diz respeito à forma. De acordo com o autor, para os antigos o Direito era autônomo, possuía fontes e características próprias; os modernos invertem as ordens, abandonam as distinções e as autonomias das artes estabelecidas pela filosofia clássica. Neste contexto, sujeitam a ciência do direito à lei

\footnotetext{
${ }^{12}$ VILLEY, Michel. O Direito e os Direitos Humanos. Tradução de Maria Ermantina de Almeida Prado Galvão. São Paulo: WMF Martins Fontes, 2007. p. 137.

${ }^{13}$ Ibidem, p. 138.

${ }^{14}$ Ibidem, p. 138.

15 Ibidem, p. 138.
}

moral - confundem a Justiça do Direito com a justiça (justeza) da moral. ${ }^{16}$

$\mathrm{O}$ terceiro e último aspecto desta corrupção diz respeito ao ânimo do pesquisador. No entender de Michel Villey, a peculiaridade da filosofia (clássica e, também, a católica) é o espírito de busca pela verdade (lux et veritas). ${ }^{17}$ Neste diapasão, de acordo com o autor, a atitude desinteressada de outrora não é mais partilhada pelos modernos: na filosofia política moderna não há honestidade e nem paixão pela verdade; as construções ideológicas foram feitas para servir aos interesses políticos específicos de seus patronos.

Neste rol incluem-se os direitos humanos, isto é, os direitos humanos surgem "corrompidos" por uma pauta política predeterminada. Afinal, de acordo com o autor, os direitos humanos surgem com propósito (ainda que dissimulado) de atender os desejos de seus criadores. ${ }^{18}$ Com esta ideia em mente, talvez o correto não seria dizer que os direitos humanos tenham sido "descobertos" (tal qual ocorre com a verdade), mas sim criados. Ademais, ainda de acordo com o autor, os direitos humanos foram criados com propósitos políticos muito específicos e nem sequer com intenções revolucionárias, mas precisamente $o$ contrário: os direitos humanos surgem com pretensões conservadoras do status quo. ${ }^{19}$

Isto porque, de acordo com Villey, o "inventor" dos direitos humanos foi Thomas Hobbes em sua magnum opus "O Leviatã", e, como é sabido, a concepção desta obra é feita a serviço dos interesses políticos da Casa dos Stuarts, ou seja, a monarquia absolutista inglesa. ${ }^{20}$ Neste diapasão é de se destacar a surpreendente conclusão trazida por Villey: a

\footnotetext{
${ }^{16}$ Ibidem, p. 140.

17 "Graça Divina e Verdade Material" (tradução livre).

${ }^{18}$ Ibidem, p. 142.

${ }^{19}$ Id. A Formação do Pensamento Jurídico Moderno. Tradução de Cláudia Berliner. São Paulo: Martins Fontes, 2005, p. 685.

${ }^{20}$ Ibidem, p. 679.
} 
Teoria dos direitos humanos surge em sua função original com propósito extraordinário e completamente contrário ao que se entende por direitos humanos hoje em dia. ${ }^{21}$ Nada de libertação e nem de resistência contra a opressão dos fortes; os direitos humanos surgem como pano de fundo para justificar o poder absoluto do Estado. Vejamos, portanto, a elaboração de Hobbes.

Nas palavras de Villey, Thomas Hobbes inicia seu trabalho com a presunçosa ambição de substituir "A Política" de Aristóteles. ${ }^{22}$ No entanto, diferente do filósofo clássico, o pensador inglês assume uma perspectiva nominalista e, influenciado por Galileu, adota o método de Pádua (resolutivo-compositivo). ${ }^{23}$ Daí a razão estrutural de seu "mito" do estado da natureza: aplicando o método de Galileu, Hobbes requer que se imagine uma condição natural em tábula rasa para depois compor um mundo composto apenas por indivíduos, transparecendo seu nominalismo. ${ }^{24}$

Ocorre que, para o que nos interessa diretamente, na construção do seu mito é a primeira vez que aparece uma definição dos direitos humanos, ao menos de acordo com Villey. ${ }^{25}$ Vejamos o trecho de "O Leviatã" de Hobbes:

$\mathrm{O}$ direito natural, a que muitos autores comumente chamam jus naturale, é a liberdade que cada homem tem de utilizar seu poder como bem the aprouver, para preservar sua própria natureza, isto é, sua vida;

\footnotetext{
${ }^{21}$ VILLEY, Michel. O Direito e os Direitos Humanos. Tradução de Maria Ermantina de Almeida Prado Galvão. São Paulo: WMF Martins Fontes, 2007, p. 142.

${ }^{22}$ Id. Filosofia do Direito: Definições e Fins do Direito: os Meios do Direito. Tradução de Márcia Valéria Martinez de Aguiar. 2a ed. São Paulo: Martins Fontes, 2008, p. 164.

${ }^{23}$ Ibidem, p. 140.

${ }^{24}$ Id. A Formação do Pensamento Jurídico Moderno. Tradução de Cláudia Berliner. São Paulo: Martins Fontes, 2005, p. 685.

${ }^{25}$ Id. O Direito e os Direitos Humanos. Tradução de Maria Ermantina de Almeida Prado Galvão. São Paulo: WMF Martins Fontes, 2007. p. 142.
}

consequentemente, é a liberdade de fazer tudo aquilo que, segundo seu julgamento e razão, é adequado para atingir esse fim. ${ }^{26}$

\section{Esta passagem é muito importante} porque demonstra que Hobbes diferente de muitos de seus antecessores aborda toda construção do Direito Natural partindo do indivíduo. Veja que na sua definição o Direito Natural limita-se aos direitos do homem. A construção de Hobbes "[...] parte do homem, pura e simplesmente". 27

Ainda no que diz respeito ao nominalismo de Hobbes, não se pode ignorar uma contraversão da filosofia de Aristóteles. Como é sabido, a filosofia do macedônio extrai o Direito da observação dos grupos sociais - "o Direito é resultante da partilha social dos bens [...] no entendimento dele as próprias sociedades eram naturais". ${ }^{28}$ Hobbes, por sua vez, faz o caminho inverso: de acordo com o autor no estado da natureza não há qualquer sociedade, apenas indivíduos. Assim sendo e, diretamente em decorrência desta inversão, Hobbes declara que o direito originário (a lei natural) é derivada da consciência do indivíduo. Neste prisma o Direito é tributário da constituição autônoma do Homem, ou seja, a "lei natural" é procedente do comportamento natural do homem de preservarse. Nos termos do pensador inglês, o Direito é a liberdade do homem de preservar sua própria natureza. ${ }^{29}$ Villey sintetiza bem esta compreensão: "o direito, em Hobbes, é extraído do indivíduo, de um individuo separado pela

\footnotetext{
${ }^{26}$ HOBBES, Thomas. Leviatã, ou Matéria, Forma e Poder de um Estado Eclesiástico e Civil. Tradução de Rosina D’Angina. 2a ed. São Paulo: Martin Claret, 2012. p. 107.

${ }^{27}$ VILLEY, Michel. op. cit., p. 144.

${ }^{28}$ Id. A Formação do Pensamento Jurídico Moderno. Tradução de Cláudia Berliner. São Paulo: Martins Fontes, 2005. p. 698.

${ }^{29}$ HOBBES, Thomas. op. cit., loc. cit.
} 
análise científica de toda ordem social preexistente $[\ldots]$ ".. ${ }^{30}$

Ocorre que a subversão sofrida pela filosofia aristotélica não para por aí. De acordo com a lição clássica, o Direito existe em si (being-in-itself); para Aristóteles, o direito era uma coisa, uma consideração concreta (um objeto). Hobbes sustenta o contrário: em seu estado da natureza não existe o Direito considerado em si, mas apenas o Direito derivado a partir da consideração sobre $o$ indivíduo, ou seja, o Direito Subjetivo: “[...] o direito não é mais uma coisa distribuída ao sujeito, mas seu atributo essencial, uma qualidade do sujeito". ${ }^{31} \mathrm{Em}$ decorrência do Direito partir do indivíduo isoladamente considerado, os direitos naturais são absolutos. A liberdade é ilimitada, afinal "[...] no ponto em que falta qualquer proibição ou obrigação [...] é permitido ao sujeito agir como quiser". ${ }^{32}$ Sendo assim, é possível afirmarmos que, em Hobbes, a liberdade no estado da natureza é ilimitada e infinita. É esta liberdade desgovernada o direito humano original. Ademais, de acordo com Villey, seguindo o mito de Hobbes, a consequência desta liberdade irrestrita é a guerra perpétua; seriam as misérias da guerra o primeiro fruto dos direitos humanos. ${ }^{33}$

Ocorre que a própria liberdade irrestrita também traz a solução para seus males, uma vez que os homens podem se utilizar de sua Razão e decidir sair do estado de natureza. Para tanto, os indivíduos firmam um contrato com o Estado ("o Deus mortal") abrindo mão de sua liberdade ilimitada em troca de ordem e paz. Só o Estado (representado pelo monarca) conserva seu direito

\footnotetext{
${ }^{30}$ VILLEY, Michel. A Formação do Pensamento Jurídico Moderno. Tradução de Cláudia Berliner. São Paulo: Martins Fontes, 2005. p. 698.

${ }^{31}$ Ibidem, p. 699.

${ }^{32}$ Id. O Direito e os Direitos Humanos. Tradução de Maria Ermantina de Almeida Prado Galvão. São Paulo: WMF Martins Fontes, 2007, p. 145.

${ }^{33}$ Ibidem, p. 147.
}

natural ilimitado. Em decorrência disso temos o Absolutismo. $^{34}$

Deste modo, como dito, Villey entende que o crédito pela invenção dos direitos humanos é de Hobbes. Não se podendo ignorar que esta construção também é responsável por brotar uma concepção inédita a respeito das finalidades do Direito moderno: o fim máximo do Direito passa a ser o indivíduo. Como dito, o Direito em si é substituído pelo Direito Subjetivo (Direito do indivíduo). ${ }^{35}$ Temos, finalmente, a invenção dos direitos humanos.

É de se mencionar, no entanto, que apesar de toda esta virada "humanista" - na teoria de Hobbes os direitos continuam não oponíveis ao Estado: "Com relação ao soberano, os súditos estão desarmados [...]”. ${ }^{36}$ Sabemos bem que não é este o papel que os direitos humanos assumem contemporaneamente; na atualidade os direitos humanos são um dos instrumentos mais fortes de luta e reivindicações por mudanças. Esta mudança de postura dos direitos humanos - esta inversão dos objetivos originários dos direitos humanos - foi realizada por John Locke. Este autor trabalha com a mesma ideia - e com a mesma estrutura "mitológica" de um estado de natureza - mas a torce para o lado contrário: serve aos interesses da oposição. ${ }^{37}$ Lembramos que, diferente de Hobbes (apadrinhado pela monarquia), Locke busca uma arma contra o Absolutismo. ${ }^{38}$

Neste contexto, afasta-se em parte da teoria de Hobbes em que os indivíduos foram forçados a criar o Estado para sobreviver ao estado de natureza, Locke entende que o Estado

\footnotetext{
${ }^{34}$ Ibidem, p. 148.

35 Id. A Formação do Pensamento Jurídico Moderno. Tradução de Cláudia Berliner. São Paulo: Martins Fontes, 2005, p. 689.

${ }^{36}$ Id. O Direito e os Direitos Humanos. Tradução de Maria Ermantina de Almeida Prado Galvão. São Paulo: WMF Martins Fontes, 2007, p. 149.

37 Note que Hobbes já havia invertido as noções fundamentais de Direito em Aristóteles. Locke subverte o que já está subvertido.

38 Ibidem, p. 150.
} 
é criado apenas para garantir uma "facilidade". Afinal, o estado de natureza não é mais necessariamente um lugar de violência, não existe razão para os indivíduos abdicarem de seus direitos; os Homens criam o Estado apenas para instituir uma força política para assegurar suas propriedades. ${ }^{39} \mathrm{O}$ Estado deixa de ser uma necessidade (Hobbes) e passa a ser um melhoramento; para Locke o Estado é um plus.

Ocorre que, ainda de acordo Locke, os direitos humanos não se restringem apenas à propriedade material, existem múltiplas propriedades e, inclusive, "liberdades abstratas" - tratam-se dos direitos extrapatrimoniais do homem. ${ }^{40}$ Destes direitos enunciados por Locke, Villey destaca a liberdade de consciência e a liberdade de opinião. É aqui que começam as verdadeiras críticas deste autor à linguagem dos direitos humanos. Na concepção de Villey, a previsão de um "direito de liberdade de consciência" é absurda: a liberdade de consciência é um atributo íntimo do homem, ninguém pode tirar a liberdade de consciência de outrem. Deste modo, não seria possível elaborar este conceito dentro de um enquadramento jurídico. Crítica semelhante é feita à ideia de liberdade de opinião - não se trata de um direito à liberdade das ideias, mas um "direito ao erro" e, além disso, um direito de propagar o erro. É partir desta elaboração de Locke que os direitos humanos começam a demonstrar sua linguagem problemática aos olhos de Villey. ${ }^{41}$

Outrossim, de acordo com Villey a doutrina do filósofo inglês é maculada precisamente pelas suas pretensões políticas. Isto porque, ao se opor à monarquia absolutista, não se pode supor que Locke estava protegendo os interesses de toda população. Permanece a

\footnotetext{
${ }^{39}$ VILLEY, Michel. O Direito e os Direitos Humanos. Tradução de Maria Ermantina de Almeida Prado Galvão. São Paulo: WMF Martins Fontes, 2007, p. 157.

${ }^{40}$ PRZETACZNIK, Franciszek. Individual Human Rights in John Locke's Two Treatises of Government. Netherlands International Law Review, 25, 1978, p. 196.
}

${ }^{41}$ VILLEY, Michel, op. cit., p. 159. opressão, troca-se apenas a classe dominante. Os direitos humanos de Locke são direitos dos ricos. De acordo com Villey, são os ricos quem podem exercer em plenitude o direito de propriedade. Semelhantemente, de acordo com o autor, o direito de liberdade de opinião é exercido apenas por aqueles com condições (e tempo livre) suficientes para educação. Em suma, seguindo a crítica de Karl Marx, ${ }^{42}$ Villey afirma que os direitos humanos de Locke são discriminatórios: "serviram para a destruição da monarquia, mas a substituíram por uma oligarquia". ${ }^{43}$ De acordo com a sombria conclusão de Villey, a dominação da classe operária pela burguesia é mais um fruto dos direitos humanos. Vejamos só que tragédia são os direitos humanos de acordo com Villey: em Hobbes, surgem como ferramenta a serviço da dominação absoluta pela monarquia; em Locke sofrem uma reformulação, mas mesmo assim os direitos humanos permanecem um instrumento de repressão, desta vez da classe burguesa contra os proletariados.

$$
\text { No entanto, além destas }
$$

"contribuições", Villey, como dito, atribui à Locke a autoria pela atual estatura dos direitos humanos. Isto porque, diferente da construção realizada por Hobbes que criara os direitos humanos para manutenção do poder secular da monarquia, em Locke estes mesmos direitos tornam-se um instrumento de resistência. ${ }^{44} \mathrm{~A}$ bem da verdade, a ideia do Direito Natural como argumento para desobediência ao Direito Positivo é a matriz do jusnaturalismo de Locke. ${ }^{45}$ Diferente do jusnaturalismo de São Tomás de Aquino em que se estabelece a primazia hierárquica do Direito Positivo sobre o Direito Natural (este deve influenciar aquele, mas, se isto não ocorre, os homens são obrigados a

\footnotetext{
${ }^{42}$ MARX, Karl. Sobre A Questão Judaica. Tradução de Nélio Schneider e Wanda Caldeira Brant. São Paulo: Boitempo, 2010, passim.

${ }^{43}$ VILLEY, Michel, op. cit., p. 161.

${ }^{44}$ Ibidem, p. 159.

${ }^{45}$ PRZETACZNIK, Franciszek, op. cit., p. 206.
} 
obedecer a lei secular), Locke entende que os direitos oriundos do Direito Natural devem ser exercidos mesmo contra o legislador. ${ }^{46}$ A nosso ver, é precisamente esta a maior contribuição de Locke para os direitos humanos. A ideia de direito à desobediência e resistência à opressão é uma das máximas da Revolução Francesa e da Declaração dos Direitos do Homem e do Cidadão, ${ }^{47}$ panteões insuperáveis da afirmação histórica dos direitos humanos. ${ }^{48}$

De todo modo, a nosso ver, as principais modificações sofridas pelos direitos humanos já foram apresentadas acima. Depois da reformulação feita por Locke, os direitos humanos passam apenas por refinamentos $\mathrm{e}$ aperfeiçoamentos, nada além disso. A infraestrutura dos direitos humanos já foi firmada, faltaria apenas o preenchimento, tarefa cumprida por Christian Wolff e encabeçada pelos seus sucessores.

\section{A HIPERTROFIA DOS DIREITOS HUMANOS EM CHRISTIAN WOLFF E AS CRÍTICAS DE MICHEL VILLEY À LINGUAGEM CONTRADITÓRIA DOS DIREITOS HUMANOS}

Se Hobbes criou os direitos humanos e Locke os inverteu para servir aos fins das "forças revolucionárias”, Christian Wolff é o responsável por hipertrofiar os direitos humanos à estatura que se encontram hoje em dia. Isto porque toda a miríade de direitos humanos que possuímos hoje são derivados dos trabalhos deste autor a respeito da natureza humana. Salvo, é claro, uma ou outra inovação decorrente do

\footnotetext{
${ }^{46}$ TROPER, Michel. A Filosofia do Direito. Tradução de Ana Deiró. São Paulo: Martins, 2008, p. 23.

${ }^{47}$ LAFER, Celso. A Reconstrução dos Direitos Humanos: Um Diálogo com o Pensamento de Hannah Arendt. São Paulo: Companhia das Letras, 1988, p. 259 e ss.

${ }^{48}$ COMPARATO, Fábio Konder. A Afirmação Histórica dos Direitos Humanos. 10 ed. São Paulo: Saraiva, 2015 , p. 140 .
}

desenvolvimento científico e sociológico. Nas palavras de Villey:

\begin{abstract}
Decerto nela [na obra de Wolff] teríamos encontrado os princípios dos direitos humanos substanciais: direito à felicidade, à saúde, à cultura etc., inferidos por Wolff do axioma de que cada um de nós tem vocação de alcançar a "felicidade", a "perfeição" de seu ser, realizado sua natureza de homem. ${ }^{49}$
\end{abstract}

Neste sentido, de acordo com Villey, a "culpa" de termos tantos direitos humanos previstos em constituições nacionais, tratados e declarações internacionais é de Wolff. Muitos autores consideram esta coletânea de direitos humanos uma coisa positiva (esta é a regra). Villey, por outro lado, considera nociva esta hiperplasia. Isto porque, de acordo com este autor, os direitos humanos são insustentáveis em si: não seria possível garantir a todos indivíduos todos os direitos humanos. De acordo com Villey, esta impossibilidade inata é maléfica porque faz com que os direitos humanos percam sua juridicidade. Ao se declararem mil direitos, mas não se garantirem todos, os direitos humanos acabam perdendo seu valor normativo; os direitos humanos deixam de ser Direito e passam a ser aspirações. ${ }^{50}$ Ao trazerem em si estas promessas insustentáveis, os direitos humanos acabam por perder seu valor. É a ambição dos direitos humanos que os condenam a possuírem um irremediável caráter ilusório, haja vista que, na sua atual extensão, são impossíveis de serem reivindicados com sucesso. Enfim, foi esta a principal "contribuição" de Wolff aos direitos humanos - tudo isto de acordo com Villey, é claro. ${ }^{51}$

\footnotetext{
${ }^{49}$ VILLEY, Michel. O Direito e os Direitos Humanos. Tradução de Maria Ermantina de Almeida Prado Galvão. São Paulo: WMF Martins Fontes, 2007. p. 161.

${ }^{50}$ Id. Filosofia do Direito: Definições e Fins do Direito: os Meios do Direito. Tradução de Márcia Valéria Martinez de Aguiar. $2^{\mathrm{a}}$ ed. São Paulo: Martins Fontes, 2008, p. 149.

${ }^{51}$ Ibidem, p. 149.
} 
Em sequência, com a soma de todos estes direitos descritos por Wolff e com o já garantido "direito à resistência" de Locke, o resultado nada surpreendente é a revolta popular. Mais um fruto dos direitos humanos, de acordo com Villey, haja vista que com as armas fornecidas por Locke e Wolff, passamos para a Revolução Francesa. ${ }^{52}$ No entanto, na elaboração de Villey, a Declaração dos Direitos do Homem e do Cidadão de 1789 não traz muita inovação, ${ }^{53}$ vai apenas repetir o que já fora estabelecido acima. Nos termos do autor, "os 'Direitos do Homem' são precisamente os direitos subjetivos naturais [...]". ${ }^{54} \mathrm{Se}$ os Revolucionários não mudaram muito a receita, não há muita diferença nas críticas (cada cabeça, uma sentença; à mesma cabeça, a mesma sentença). Neste sentido, ao comentar a Declaração, Villey acaba por repetir as críticas que mencionamos acima quando tratamos de Wolff.

É de se destacar, no entanto, as ponderações mencionadas por Villey seguindo a crítica de Marx ${ }^{55}$ a respeito do "pseudouniversalismo" dos direitos do homem. Isto porque, nos termos da conhecida crítica marxista aos direitos humanos, o problema é que todas estas declarações criam apenas "direitos formais", isto é "[...] formalmente iguais para todos, mas de fato reservadas aos ricos". ${ }^{56} \mathrm{~A}$

\footnotetext{
${ }^{52}$ VILLEY, Michel. O Direito e os Direitos Humanos. Tradução de Maria Ermantina de Almeida Prado Galvão. São Paulo: WMF Martins Fontes, 2007, p. 161.

${ }^{53}$ Merece destaque, no entanto, uma singela consideração que revela o mais alto Nominalismo dos Revolucionários. Trata-se do artigo segundo, primeira parte, da Declaração: “Art. $2^{\circ}$. a finalidade de toda associação política é a conservação dos direitos naturais e imprescritíveis do homem [...]". A passagem chama a atenção, mas, do mesmo modo, não é nada além de repetições da construção já realizada por Hobbes e Locke.

${ }^{54}$ Id. Filosofia do Direito: Definições e Fins do Direito: os Meios do Direito. Tradução de Márcia Valéria Martinez de Aguiar. 2a ed. São Paulo: Martins Fontes, 2008, p. 148.

${ }^{55}$ HAMACHER, Werner; DE JESÚS, Ronald Mendoza. On the Right to Have Rights: Human Rights; Marx and Arendt. The New Centennial Review, Vol. 14, N. 2, Law and Violence, 2014, p. 178.

${ }^{56}$ VILLEY, Michel. op. cit., p. 155.
}

bem da verdade, esta crítica já fora feita anteriormente quando falávamos de Locke. Sustenta-se que os direitos humanos surgem apenas para garantir direitos para uma determinada elite; não são realmente destinados a todos haja vista que criam prerrogativas que não poderiam ser aproveitadas por aqueles sem determinado patamar financeiro. São direitos dos ricos. No entanto, Villey menciona que ao menos Locke tinha a "honestidade" de admitir que seus direitos eram voltados apenas para os proprietários. Os Revolucionários franceses escondem a discriminação inata dos direitos humanos sob a falsa alegação de um universalismo; apesar da "[...] aparência de proporcionar a todos satisfações infinitas, o sistema gira em benefício de alguns". 57

De toda feita, semelhante ao que ocorre com a Declaração Revolucionária, é de se mencionar que todas estas críticas também se repetem na análise dos direitos humanos sob os auspícios das Nações Unidas. Afinal, na base da estrutura dos direitos humanos contemporâneos encontramos a Declaração Universal dos Direitos Humanos - DUDH e esta (do mesmo modo que a Declaração antecedente) não inova em muita coisa. Sendo assim, em sentido idêntico ao que falávamos acima a respeito de Wolff e da Declaração de 1789, aos olhos de Villey, a DUDH é insustentável. Não possuindo, de acordo com o autor, qualquer eficácia modificativa real; enuncia muito, mas não conquista nada. Segue a mesma receita que suas antecessoras: "pois não temos a impressão de que textos tais como as Declarações dos Diretos das Nações Unidas nos tenham de fato proporcionado saúde perfeita, lazeres e boa cultura." 58 Outrossim, de acordo com Villey a Declaração Universal de Direitos Humanos já peca no título. Isto porque, nos termos da já mencionada crítica de origem marxista, estes

\footnotetext{
${ }^{57}$ Ibidem, p. 180.

${ }^{58}$ Ibidem, p. 149.
} 
direitos estão longe de serem realmente universais. Pretendem sê-lo, mas nunca o serão por completo, haja vista que, além de seus problemas ideológicos, econômicos e estruturais, na sua hipertrofia tornaram-se contraditórios. ${ }^{59}$

Finalmente chegamos a que é, em nossa concepção, a principal crítica de Villey à linguagem dos direitos humanos: sua suposta contradição inata. Isto porque, conforme o autor o real problema da concretização dos direitos humanos não é apenas a insuficiência econômica, mas sim porque na sua multitude os direitos humanos tornam-se contraditórios e inconciliáveis. Nas palavras do autor:

Não conseguimos mais conciliar estes direitos que nossa época secreta em todos sentidos: direitos ao pudor e à liberdade sexual, direitos à vida, e à interrupção da gravidez, direito ao casamento e ao divórcio, direito à informação escrita e televisionada assim como ao silêncio, direito "à cidade", às moradias populares e a qualidade de vida. ${ }^{60}$

Percebemos que, de acordo com Villey, em Hobbes e Locke os direitos humanos já apresentavam defeitos inatos e corrupções ideológicas. A mencionada contradição inata já existia, seja por subverter toda a fundamentação jurídica antecedente (em especial os ensinamentos de Aristóteles), seja por prometer direitos não-materiais (os direitos à liberdade de expressão e consciência dentre outros). No entanto, até então, eles ainda possuíam um ligamento mínimo com a realidade. Ocorre que, de acordo com Villey, a partir da hipertrofia escalonada que sofreram no decorrer dos anos, os direitos humanos perdem qualquer vínculo com o plano fático; tornam-se uma panaceia milagrosa sem qualquer pretensão de serem

\footnotetext{
${ }^{59}$ VILLEY, Michel. Filosofia do Direito: Definições $e$ Fins do Direito: os Meios do Direito. Tradução de Márcia Valéria Martinez de Aguiar. 2 ${ }^{\mathrm{a}}$ ed. São Paulo: Martins Fontes, 2008, p. 154.
}

${ }^{60}$ Ibidem. materializáveis. Os direitos humanos tornam-se irrealizáveis. ${ }^{61}$

Em trecho bastante representativo do problema do autor com a contradição dos direitos humanos, Villey menciona o "direito à felicidade" previsto na Constituição dos Estados Unidos da América e apresenta o seguinte paradoxo: se a felicidade de alguém é matar outrem, como conciliar este direito com o direito à vida ${ }^{62}$

Sendo assim, de acordo com Villey, no seu atual estágio os direitos humanos não são Direito, mas apenas representam as aspirações políticas de uma sociedade. ${ }^{63}$ Como dito, não se pode pretender concretizar os direitos humanos tais como ocorre com o Direito em geral e se alguém tentasse não haveria de ter sucesso. Em suas palavras: "quando nos é atribuído um direito, esperamos de nossa parte que este direito seja realmente devido, e possa ser reivindicado com alguma chance de sucesso. Não é o caso dos 'direitos do homem'". ${ }^{64}$ Precisamente por serem intrinsecamente contraditórios, tornam-se irrealizáveis. Em razão desta "impossibilidade inata" não poderiam jamais ser Direito. Melhor dizendo: Villey afirma que os direitos humanos seriam contraditórios e, por serem contraditórios seriam irrealizáveis; uma vez irrealizáveis, os direitos humanos não seriam Direito. ${ }^{65}$

Outrossim, de acordo com o autor, os direitos humanos não são uma criação de juristas; Hobbes, Locke e seus sucessores não são entendedores do Direito ${ }^{66} \mathrm{e}$, nas suas atribulações criativas, são responsáveis por um

\footnotetext{
${ }^{61}$ Ibidem, p. 178.

${ }^{62}$ Id. O Direito e os Direitos Humanos. Tradução de Maria Ermantina de Almeida Prado Galvão. São Paulo: WMF Martins Fontes, 2007, p. 06.

${ }^{63}$ Ibidem.

${ }^{64}$ Id. Filosofia do Direito: Definições e Fins do Direito: os Meios do Direito. Tradução de Márcia Valéria Martinez de Aguiar. $2^{\mathrm{a}}$ ed. São Paulo: Martins Fontes, 2008, p. 155.

${ }^{65}$ Ibidem, p. 178.

${ }^{66}$ VILLEY, Michel. O Direito e os Direitos Humanos. Tradução de Maria Ermantina de Almeida Prado Galvão. São Paulo: WMF Martins Fontes, 2007, p. 152.
} 
direito que não é Direito ("o aparecimento dos direitos humanos atesta a decomposição do conceito do direito"). ${ }^{67}$ Neste diapasão, o problema da linguagem contraditória dos direitos humanos surgiria por uma tentativa de adaptar gramáticas incompatíveis. Tenta-se introduzir no Direito ideias que não possuem espaço de existência no meio jurídico. Tendo em vista que os direitos humanos não seriam (de acordo com o autor) um tema jurídico, de igual modo sua linguagem também não seguiria as especificidades técnicas do Direito.

A consequência desta falta de correlação é que qualquer tentativa de trazer os direitos humanos para o Direito faria com que a linguagem se tornasse ilusória e contraditória: "linguagem indistinta, perigosamente imprecisa, geradora de ilusões e de falsas reivindicações impossíveis de satisfazer". ${ }^{68}$ Teríamos um "erro de tradução". A nosso ver é precisamente em razão deste conflito de linguagens que Villey critica a indeterminação contraditória dos direitos humanos. De acordo com o autor, as declarações universais concedem os mais diversos direitos, mas não se preocupam em definir seus limites de atuação e isto comprometeria sua eficácia. ${ }^{69}$ Os direitos humanos seriam intrinsecamente ineficazes.

Esta obscuridade linguística, na visão do autor, seria uma das razões para concluir que os direitos humanos não seriam Direito. ${ }^{70}$ Como já mencionado, na visão do autor é impossível que o Direito trabalhe com institutos que apresentam tamanha contradição intrínseca, haja vista que a Ciência Jurídica preza pela concretude, pela modificação do mundo. Se um direito é irrealizável em si mesmo, não poderia

\footnotetext{
${ }^{67}$ VILLEY, Michel. O Direito e os Direitos Humanos. Tradução de Maria Ermantina de Almeida Prado Galvão. São Paulo: WMF Martins Fontes, 2007. p. 163.

${ }^{68}$ Ibidem, loc. cit.

${ }^{69}$ Ibidem, p. 7.

${ }^{70}$ Id. Filosofia do Direito: Definições e Fins do Direito: os Meios do Direito. Tradução de Márcia Valéria Martinez de Aguiar. $2^{\text {a }}$ ed. São Paulo: Martins Fontes, 2008, p. 159.
}

jamais ser Direito. ${ }^{71}$ Nesta linha, o autor conclui que os direitos humanos não são um progresso. Seriam uma religião falsa com promessas impossíveis de serem atendidas precisamente por faltarem-lhe qualquer concretude. ${ }^{72}$

Ocorre que não subscrevemos à esta conclusão. Como mencionado no início do trabalho, entendemos que a aparente contradição linguística apresentada pelos direitos humanos não é insuperável. A realidade é que, a nosso ver, falta na crítica de Villey a análise das técnicas de solução dos conflitos entre direitos humanos. Além disso, nos termos do exposto acima, percebemos que Villey por vezes confunde os critérios de validade da norma com um juízo de eficácia da norma. É o que veremos a seguir.

\section{A FALHA NA ACUSAÇÃO DE MICHEL VILLEY: UM DESFECHO À SUPOSTA CONTRADIÇÃO INATA DOS DIREITOS HUMANOS}

Nos termos do examinado nas páginas antecedentes, é possível traçarmos a seguinte sequência de ideias em Villey: os direitos humanos são hipertrofiados e, em razão disto, tornaram-se contraditórios; esta linguagem contraditória não é própria do Direito; por padecerem desta contradição inata, os direitos humanos não são Direito, apenas ideais e aspirações políticas.

Como dito, nós discordamos da conclusão do autor. Entendemos possível solucionar esta suposta contradição entre direitos humanos conflitantes a partir de determinadas fórmulas, em especial as técnicas das Teorias Interna e Externa. Além disso, entendemos que esta suposta contradição entre direitos não é sequer um fenômeno extraordinário ou externo à Ciência Jurídica. Pelo contrário: a nosso ver, o problema apresentado por Villey não é nada

\footnotetext{
${ }^{71}$ Ibidem, p. 157.

72 Ibidem, p. 163.
} 
além de uma colisão de direitos em sentido em sentido amplo. ${ }^{73}$ Neste diapasão, a nosso ver, esta suposta contradição não é suficiente para condenar os direitos humanos a não serem Direito.

Primeiramente, é de se ressaltar que, de fato, este problema seria insolucionável caso os juristas defendessem a ideia de direitos humanos absolutos. Não é caso, contudo. Na atualidade reconhecemos que os direitos humanos são relativos, admitindo limitações tanto pela sua redação positivada quanto na interação com os demais direitos humanos. ${ }^{74}$ Em outras palavras: em sua interação concreta, os direitos humanos são limitáveis entre si. ${ }^{75}$ Sendo assim, mesmo que aparentemente os direitos humanos não possuam limites em seu texto originário, esses direitos serão delimitados caso a caso. Deste modo, o problema da aparente contradição inata dos direitos humanos não é insolucionável.

Nesta senda, no desenvolvimento da Teoria dos Direitos Humanos a primeira fórmula que encontramos para solucionar as contradições (colisões) entre direitos é a da Teoria Interna. A ideia desta técnica é que ao determinarmos o verdadeiro conteúdo da norma veremos que, na realidade, não existem conflitos (todos os conflitos seriam aparentes). ${ }^{76}$ Isto porque, de acordo com Alexy, nas "teorias internas" todos os direitos humanos possuiriam limites interiores, definidos a priori pela própria norma (sejam estes limites expressos ou imanentes). ${ }^{77}$ Sendo assim, na Teoria Interna não haveriam conflitos reais (não existem contradições

\footnotetext{
73 SOUZA NETO, Cláudio Pereira de; SARMENTO, Daniel. Direito Constitucional: Teoria, História e Métodos de Trabalho. $2^{a}$ ed. Belo Horizonte: Fórum, 2014, p. 497

74 RAMOS, André de Carvalho. Curso de Direitos Humanos. $3^{\text {a }}$ ed. São Paulo: Saraiva, 2016, p. 112

${ }^{75}$ Id. Teoria Geral dos Direitos Humanos na Ordem Internacional. 6 ${ }^{\mathrm{a}}$ ed. São Paulo: Saraiva, 2016, p. 283.

${ }^{76}$ Id. Curso de Direitos Humanos. $3^{\mathrm{a}}$ ed. São Paulo: Saraiva, 2016, p. 114

${ }_{77}$ ALEXY, Robert. Teoria dos Direitos Fundamentais. Tradução de Virgílio Afonso da Silva. $2^{\mathrm{a}}$ ed. São Paulo:
} Malheiros Editores, 2011, p. 287. concretas), mas apenas a aparência destas. Esta Teoria Interna defende, portanto, a existência de limites intrínsecos a todos os direitos, ainda que estes não estejam expressamente discriminados. Isto faz com que seja impossível um direito colidir com o outro; caso se imagine estar diante de um conflito de direitos humanos, na realidade o que ocorre é que um destes direitos nunca realmente incidiu naquele caso concreto. ${ }^{78}$

Um dos exemplos mais clássicos de aplicação desta teoria é retirado do julgamento do caso "Schenck vs. United States" de 1919. Na lição irretocável de André de Carvalho Ramos:

O clássico exemplo de limite imanente é o do homem que grita falsamente "fogo" em uma sala de cinema lotada, violando com sua conduta a integridade física daqueles que foram pisoteados pelo pânico gerado. A liberdade de expressão nunca teria incidido, pois ela não alberga a conduta de gritar fogo falsamente em um cinema lotado. Nunca existiu conflito entre direitos, pois aquele que assim agiu, atuou sem amparo de qualquer direito, pois a liberdade de expressão não protege esse tipo de conduta abusiva. ${ }^{79}$

A nosso ver, a técnica sugerida pela Teoria Interna já seria suficiente para resolver o paradoxo mencionado por Villey que citamos anteriormente. ${ }^{80} \mathrm{Na}$ realidade, entre o direito à felicidade e o direito à vida, não existe conflito, haja vista que direito de felicidade não alberga o de matar outra pessoa. Contudo, admitimos que esta primeira técnica não é perfeita, sendo possível, inclusive visualizarmos diversos casos difíceis (hard cases) em que não seria praticável delimitar de forma clara o conteúdo dos direitos em exame. Por isso que existe a Teoria Externa. 81

\footnotetext{
${ }^{78}$ RAMOS, André de Carvalho. op. cit., loc. cit.

79 Ibidem.

${ }^{80}$ VILLEY, Michel. O Direito e os Direitos Humanos. Tradução de Maria Ermantina de Almeida Prado Galvão. São Paulo: WMF Martins Fontes, 2007, p. 6.

81 RAMOS, André de Carvalho. Curso de Direitos
} Humanos. $3^{\mathrm{a}}$ ed. São Paulo: Saraiva, 2016. p. 116. 
Esta outra teoria se utiliza do elaborado pela Teoria Interna, mas vai um passo além. $\mathrm{Na}$ aplicação da Teoria Externa primeiramente utilizaríamos a ideia de delimitação do direito que, à primeira vista, incide sobre a situação fática (identifica-se o direito que por ventura incide no caso concreto). Em um segundo momento (caso a situação fática se amolde no texto daquele primeiro direito) devemos analisar a existência de limites razoáveis impostos por outros direitos de forma a impedir que aquele primeiro direito aparente possa ser considerado um direito definitivo. ${ }^{82}$

Novamente, vamos nos utilizar do exemplo de Villey ${ }^{83}$ para testar a fórmula. No caso, o autor traz primeiramente o direito à felicidade (direito aparente), na aplicação da Teoria Externa devemos primeiramente realizar uma consideração para saber se o direito à felicidade abarcaria a possibilidade de matar outrem para que o pretenso homicida seja feliz. Somos forçados a admitir que, dentro de uma interpretação seca e literal deste direito à felicidade, em um primeiro momento é possível afirmar que o direito à felicidade abarcaria o homicídio neste caso concreto. No entanto, felizmente, temos a aplicação da segunda parte da Teoria Externa. Neste segundo momento, devemos ver se o direito aparente (direito a felicidade) poderia, no caso concreto, ser limitado justificadamente por outros direitos. Neste caso, a nosso ver, a limitação é inteiramente plausível: o direito à felicidade seria limitado pelo direito à vida de outrem.

Observe-se que, diferente da Teoria Interna, a Teoria Externa admite conflitos (contradições) entre os direitos, mas isto não faz com que os direitos humanos deixem de ser

\footnotetext{
${ }^{82}$ ARAGÃO, João Carlos Medeiros. Choque entre Direitos Fundamentais: Consenso ou Controvérsia?. Revista de Informação Legislativa, Brasília, a. 48, n. 189, 2011, p. 264-265.

${ }^{83}$ VILLEY, Michel. O Direito e os Direitos Humanos. Tradução de Maria Ermantina de Almeida Prado Galvão.
} São Paulo: WMF Martins Fontes, 2007. p. 6.
Direito. Ao contrário, a Teoria Externa é precisamente uma fórmula jurídica de solução de problemas oriundos da colisão entre normas jurídicas; a colisão entre direitos é um fenômeno inteiramente tolerável e, inclusive, próprio da Ciência Jurídica.

Ademais, chamamos atenção ao fato que não se está falando aqui em hierarquia de direitos humanos - não dissemos que o pretenso direito à felicidade estaria subordinado ao direito à vida. $\mathrm{O}$ que fizemos foi uma análise do real alcance concreto da norma de direitos humanos a partir do critério da Proporcionalidade. ${ }^{84}$ Vejamos, portanto, que uma das premissas basilares para o bom funcionamento da Teoria Externa é a aplicação do Princípio da Proporcionalidade. ${ }^{85}$ Não ignoramos que apesar das mais diversas elaborações jurídicas a respeito dos elementos da Proporcionalidade este não deixa de ser um critério subjetivo. Mas a realidade é que esta é a condição insuperável do Direito que (se é que de fato é uma Ciência) não será jamais uma Ciência Exata.

Mesmo que assim não fosse, ainda seria possível suplantar a crítica de Michel Villey. Isto porque, como dissemos acima, o autor afirma que os direitos humanos seriam contraditórios e, por serem contraditórios seriam irrealizáveis (uma vez irrealizáveis, os direitos humanos não seriam Direito), ${ }^{86}$ no entanto, entendemos que ainda que não fosse possível solucionar estas contradições (ainda que não existissem as fórmulas que apresentamos acima) a crítica de Villey permaneceria insustentável. Afinal, nas suas acusações, Villey comete uma impropriedade normativa: confunde validade com eficácia da norma.

\footnotetext{
84 MARMELSTEIN, George. Curso de Direitos Fundamentais. $6^{a}$ ed. São Paulo: Atlas, 2016, p. 388.

${ }^{85}$ RAMOS, André de Carvalho. op. cit., loc. cit.

${ }^{86}$ VILLEY, Michel. Filosofia do Direito: Definições e Fins do Direito: os Meios do Direito. Tradução de Márcia Valéria Martinez de Aguiar. $2^{\text {a }}$ ed. São Paulo: Martins Fontes, 2008, p. 178.
} 
Nos termos dos fundamentos basilares da Teoria Geral da Norma Jurídica, temos que uma norma possui três critérios de valoração: justiça, validade e eficácia. Inclusive, é de se ressaltar que se tratam de três problemas distintos e inconfundíveis, além de completamente independentes. ${ }^{87}$ Desta feita, de acordo com Bobbio, é possível que uma norma seja válida, justa, mas ineficaz; também é possível o contrário, norma eficaz, justa, mas inválida, ou quaisquer combinações imagináveis destes três critérios (são independentes, afinal). ${ }^{88}$ Tal constatação configura um dos elementos basilares da compreensão da Teoria do Direito Positivo. Não é possível reduzir o escopo de validade de uma norma jurídica (se a norma é válida ou inválida) à sua eficácia: “[...] a eficácia de uma ordem jurídica não é, tampouco como o fato que a estabelece, fundamento da validade". ${ }^{89}$

Nesta linha de ideias, a nosso ver, Villey comete uma impropriedade normativa. Ao afirmar que os direitos humanos não seriam Direito por estes não serem realizáveis, o autor confunde validade com eficácia. O problema da validade é uma questão de análise de existência da norma, não havendo qualquer espaço para realizarmos juízos de valor sobre sua justiça ou eficácia. Dizer que uma norma é Direito ou não, é apenas uma questão de caráter objetivo ("juízo de fato"). ${ }^{90}$ Por outro lado, o problema da eficácia é que se demanda uma análise de concretude fática da norma, isto é, quando se analisa a eficácia é que se verifica se aquela norma é seguida ou não pelas pessoas e pelo Estado. No dizer de Bobbio: "que uma norma exista como norma jurídica não implica que seja

\footnotetext{
87 BOBBIO, Norberto. Teoria da Norma Jurídica. Tradução de Fernando Pavan Baptista e Ariani Bueno Sudatti. Bauru: Edipro, 2001, p. 45

${ }^{88}$ Ibidem, p. 49

${ }^{89}$ KELSEN, Hans. Teoria Pura do Direito. Tradução de João Baptista Machado. $6^{\text {a }}$ ed. São Paulo: Martins Fontes, 1998 , p. 148.

${ }^{90}$ BOBBIO, Norberto. op. cit., p. 46
}

também constantemente seguida." 91 Neste contexto, como já mencionado, uma norma pode ser válida sem ser eficaz. Sendo assim, ainda que se admita que os direitos humanos são irrealizáveis por serem contraditórios, isto não faz com que estes deixem de ser Direito.

Tantas normas no mundo jurídico são ineficazes e nem por isso deixam de ser normas, não seria diferente nos direitos humanos. Deste modo, ainda que ignoremos todas as possibilidades de solução dos conflitos (contradições) entre os direitos que foram apresentadas acima, o argumento de Villey não se sustenta. Norma válida (Direito) pode ser ineficaz sem que isto retire seu caráter jurídico.

De toda feita, partimos com o objetivo principal de demonstrar que a suposta contradição inata dos direitos humanos em sua multitude contemporânea não é suficiente para os expulsarmos do conjunto do que é Direito. Potencialmente, seria esta "contradição" terminológica que reforçaria o fato dos direitos humanos serem Direito: a colisão de direitos é um fenômeno tipicamente jurídico. Além disso, demonstramos que as ideias de validade e eficácia da norma não se confundem, sendo plenamente possível uma norma válida, mas ineficaz. Sendo assim, ainda que se admita a acusação da insustentabilidade inata dos direitos humanos em razão de sua suposta contradição inata, a crítica de Villey não se sustenta: a norma ineficaz ainda é Direito.

\section{CONCLUSÃO}

Nas páginas antecedentes realizamos uma breve exposição da Teoria dos direitos humanos em Michel Villey. Apresentamos, ainda que de forma sucinta, suas considerações sobre a inexistência de direitos humanos antes do Século XVII, em especial na Filosofia Canônica, em Roma e na Grécia Antiga. Depois desta

${ }^{91}$ Ibidem, p. 47. 
recontagem, realizamos uma análise da invenção e desenvolvimento dos direitos humanos em Hobbes, Locke e Wolff. A seguir, trouxemos alguma das críticas de Michel Villey a respeito dos direitos humanos, especificamente sua alegação de que estes não poderiam ser Direito, haja vista que seriam contraditórios e, portanto, irrealizáveis.

Finalmente, trouxemos nossas ideias com o propósito de rebater a crítica de Villey. Apresentamos a Teoria Interna e a Teoria Externa e a possibilidade de solucionarmos de forma jurídica as supostas contradições entre os direitos humanos. Vimos, inclusive, que se solucionarmos o problema utilizando da Teoria Interna não há que se falar sequer em contradição entre os direitos humanos, mas apenas um "conflito aparente". Por outro lado, caso utilizemos da Teoria Externa veremos que é possível admitir a existência de conflitos (contradições) entre os direitos humanos, mas isso não faz com que estes deixem de ser Direito. A colisão de direitos é um fenômeno tipicamente jurídico.

Além disso, demonstramos que a crítica de Villey parte de uma premissa imperfeita, haja vista que, ao afirmar que os direitos humanos não seriam direito por serem supostamente irrealizáveis, o autor confunde eficácia com validade da norma. Vimos que na Teoria Geral da Norma, estes elementos são independentes e, sendo assim, ainda que se admita que os direitos humanos sejam irrealizáveis, eles permaneceriam sendo norma válida (mesmo que norma ineficaz).

Nossos objetivos na realização deste trabalho foram dois: expor a Teoria dos Direitos Humanos em Michel Villey (objetivo secundário) e rebater a mencionada crítica do autor, concluindo que é possível admitir uma suposta linguagem contraditória nos direitos humanos sem que isso faça com que estes percam seu caráter jurídico (objetivo principal).
Entendemos que estes objetivos foram alcançados, ainda que de modo conciso. Não ignoramos que o tema dos direitos humanos é muito rico. Além disso, as críticas de Michel Villey são muitas e entendemos que em várias destas críticas existe espaço para uma contestação em favor dos direitos humanos.

No entanto, não queremos com isso desmerecer a contribuição feita por este autor. Ao contrário. Criticar a "religião dos direitos humanos" é muito importante. Todavia, no que diz respeito à crítica especificamente enfrentada no presente artigo, entendemos que Villey não tem razão. Não é possível pretender um Direito livre de termos imprecisos e até mesmo contraditórios. É esta a sina das Ciências Humanas. Por outro lado, não se pode também admitir um Direito sem o mínimo sustentáculo junto à realidade. Neste aspecto a crítica de Villey faz sentido. A nosso ver, é preciso que os operadores do Direito tenham o cuidado de não se deixarem seduzir pela poesia das promessas infinitas. Afinal, parafraseando Villey, ${ }^{92}$ é tentador prometer o infinito, mas depois não podemos nos surpreender quando a promessa não for cumprida.

92 VILLEY, Michel. O Direito e os Direitos Humanos. Tradução de Maria Ermantina de Almeida Prado Galvão. São Paulo: WMF Martins Fontes, 2007. p. 06. 


\section{REFERÊNCIAS}

COMPARATO, Fábio Konder. A Afirmação Histórica dos Direitos Humanos. 10 ed. São Paulo: Saraiva, 2015.

HAMACHER, Werner; DE JESÚS, Ronald Mendoza. On the Right to Have Rights: Human Rights; Marx and Arendt. The New Centennial Review, Vol. 14, N. 2, Law and Violence, 2014, p. 178.

HOBBES, Thomas. Leviatã, ou Matéria, Forma e Poder de um Estado Eclesiástico e Civil. Tradução de Rosina D’Angina. 2ª ed. São Paulo: Martin Claret, 2012.

KELSEN, Hans. Teoria Pura do Direito. Tradução de João Baptista Machado. 6 a ed. São Paulo: Martins Fontes, 1998.

LAFER, Celso. A Reconstrução dos Direitos Humanos: um Diálogo com o Pensamento de Hannah Arendt. São Paulo: Companhia das Letras, 1988.

MARX, Karl. Sobre A Questão Judaica. Tradução de Nélio Schneider e Wanda Caldeira Brant. São Paulo: Boitempo, 2010.

PRZETACZNIK, Franciszek. Individual Human Rights in John Locke's Two Treatises of Government. Netherlands International Law Review, 25, 1978.

RAMOS, André de Carvalho. Curso de Direitos Humanos. 3. ed. São Paulo: Saraiva, 2016.

RAMOS, André de Carvalho. Teoria Geral dos Direitos Humanos na Ordem Internacional. 6. ed. São Paulo: Saraiva, 2016.

SOUZA NETO, Cláudio Pereira de; SARMENTO, Daniel. Direito Constitucional: Teoria, História e Métodos de Trabalho. 2. ed. Belo Horizonte: Fórum, 2014.

TROPER, Michel. A Filosofia do Direito. Tradução de Ana Deiró. São Paulo: Martins, 2008.

VILLEY, Michel. A Formação do Pensamento Jurídico Moderno. Tradução de Cláudia Berliner. São Paulo: Martins Fontes, 2005.

VILLEY, Michel. Filosofia do Direito: Definições e Fins do Direito: os Meios do Direito. Tradução de Márcia Valéria Martinez de Aguiar. 2ª ed. São Paulo: Martins Fontes, 2008.

VILlEY, Michel. O Direito e os Direitos Humanos. Tradução de Maria Ermantina de Almeida Prado Galvão. São Paulo: WMF Martins Fontes, 2007.

Recebido em: 22/10/2017

Aceito em: 07/11/2018 
